\title{
Erratum to: Using immersive virtual reality and anatomically correct computer-generated characters in the forensic assessment of deviant sexual preferences
}

Dominique Trottier $^{4} \cdot$ Patrice Renaud $^{1,2,3} \cdot$ Joanne-Lucine Rouleau $^{4}$.

Mathieu Goyette $^{2} \cdot$ Chantal Saumur $^{2} \cdot$ Tarik Boukhalfi $^{2} \cdot$ Stéphane Bouchard $^{2}$

Published online: 6 October 2015

(c) Springer-Verlag London 2015

\section{Erratum to: Virtual Reality (2014) 18:37-47 \\ DOI 10.1007/s10055-013-0235-8}

The authorship of this paper should read as follows: Trottier, D., Renaud, P., Rouleau, J.-L., Goyette, M., Saumur, C., Boukhalfi, T., and Bouchard, S. This authorship change has been approved by all authors and the Editors-in-Chief.

The online version of the original article can be found under doi:10.1007/s10055-013-0235-8.

Patrice Renaud

patrice.renaud@uqo.ca

1 Psychology and Psychoeducation Department, Université du Québec en Outaouais, Gatineau, Canada

2 Institut Philippe-Pinel de Montréal, Montreal, Canada

3 Module de Psychologie, 283 Alexandre-Taché Boulevard, Room C2803, C.P. 1250 Succursale Hull, Gatineau J8X 3X7,

Canada

4 Department of Psychology, Université de Montréal, Montreal, Canada 